\title{
HUBUNGAN KENDALI GULA DARAH DENGAN FAAL PARU PADA PASIEN DIABETES MELITUS DI POLI ENDOKRIN RSUP Prof. Dr. R. D. KANDOU MANADO
}

\author{
${ }^{1}$ Meggy R. Kowaas \\ ${ }^{2}$ Karel Pandelaki \\ ${ }^{2}$ M.C.P.Wongkar
}

\author{
${ }^{1}$ Kandidat Skripsi Fakultas Kedokteran Universitas Sam Ratulangi Manado \\ ${ }^{2}$ Bagian Ilmu Penyakit Dalam BLU RSU Prof. Dr. R. D. Kandou Manado \\ E-mail: mkowaas11_035@yahoo.co.id
}

\begin{abstract}
One of DM target organ is lung. DM can cause decreasing of lung capacity because the effect of hyperglycemic in a long period of time. The high level of HbA1c linked with fast progresivity of complication on microvascular. This research is aiming to find out the correlation of blood sugar control (HbA1c) with lung function (FEV1 / forced expiratory Volume in 1 second and FVC/ forced vital capacity). This research used cross-sectional design. The sample on this research total of 30 DM type-2 patients that came at Poli Endokrin RSUP Prof.Dr. R.D. Kandou Manado in the period of November to December 2014. Data registration was taken on medical record about the level of HbA1c and carried out measurement of the patient's height and weight and followed by spirometry test. After that the correlation of blood sugar control with FVC and FEV1 was tested with using Pearson correlation test. Pearson correlation test shows that there was negatif and not significant correlation between HbA1c level with FEV1 $(r=-0,251, p=0,181)$ and HbA1c level with FCV $(\mathrm{r}=-0,079, \mathrm{p}=0,679)$, in spite of clinically there was decreasing of KVP on $5 \mathrm{DM}$ patients. Conclusion: There's no significant correlation between high level of HbA1c with FEV1 and FVC decreased.
\end{abstract}

Keywords: HbA1c, FEV1, FVC

\begin{abstract}
Abstrak: Salah satu organ target dari DM adalah paru. Penurunan kapasitas paru bisa disebabkan pengaruh hiperglikemia dalam waktu yang lama. Kadar HbA1c yang tinggi dihubungkan dengan progreisfitas komplikasi yang cepat pada mikrovaskular. Penelitian ini bertujuan untuk mengetahui hubungan kendali gula darah (HbA1c) dengan fungsi paru (VEP1/ volume ekspirasi paksa detik pertama dan KVP/ kapasitas vital paru). Penelitian ini menggunakan desain cross-sectional dengan sampel peneltian ini berjumlah 30 orang pasien DM tipe 2 yang datang di Poli Endokrin RSUP Prof. Dr. R.D. Kandou Manado periode November sampai Desember 2014. Dilakukan pencatatan data dari rekam medis mengenai kadar HbA1c dan dilakukan pengukuran berat badan dan tinggi badan pasien kemudian dilakukan uji spirometri. Hubungan kendali gula darah dengan KVP dan $\mathrm{VEP}_{1}$ diuji dengan menggunakan uji korelasi pearson. Uji korelasi Pearson menunjukkan bahwa terdapat hubungan negatif dan tidak signifikan antara kadar HbA1c dengan VEP1 ( $r=-0,251$, $\mathrm{p}=0,181)$ dan kadar HbA1c dengan KVP $(r=-0,079, \quad p=0,679)$, meskipun secara klinis terdapat penurunan KVP pada 5 orang pasien DM. Ssimpulan: Tidak terdapat hubungan yang signifikan antara meningkatnya kadar HbA1c dengan penurunan VEP1 dan KVP.
\end{abstract}

Kata kunci: HbA1c, VEP1, KVP 
Menurut American Diabetes Association (ADA) 2010, diabetes melitus adalah suatu kelompok penyakit metabolik dengan karakteristik hiperglikemia yang terjadi karena kelainan sekresi insulin, kerja insulin atau kedua-duanya. ${ }^{1}$ Terdapat kecenderungan peningkatan angka insidensi dan prevalens diabetes melitus tipe 2 di seluruh dunia., ${ }^{1,3}$ WHO memperkirakan lebih dari 180 juta orang di dunia dengan diabetes dan di tahun 2030 jumlahnya bertambah dua kali lipat. ${ }^{1,4}$ Prevalens diabetes melitus di Indonesia mencapai $6,6 \%$ pada laki-laki dan 7,1\% pada perempuan dengan prevalens untuk total populasi sebesar $6.9 \% .{ }^{4,5}$ Disebutkan Riskesdas dalam wawancara (berdasarkan jawaban responden yang pernah didiagnosis tenaga kesehatan dan gejala klinis) terjadi peningkatan prevalensi diabetes melitus dari 1,1\% (2007) menjadi 2,1\% (2013). Prevalensi diabetes yang terdiagnosis dokter atau gejala, tertinggi terdapat di Sulawesi Tengah (3,7\%), Sulawesi Utara (3,6\%), Sulawesi Selatan $(3,4 \%)$, Nusa Tenggara Timur $(3,3 \%){ }^{2}$

Pemeriksaaan lab HbA1c merupakan standar emas untuk menilai kendali gula darah. ${ }^{8}$ Nilai interpretasi dari nilai kontrol glukosa melalui kadar glikat hemoglobin adalah normal atau terkontrol adalah kurang dari $7 \%$ dan tidak terkontrol adalah lebih dari $7 \%{ }^{1,12}$

Salah satu fungsi organ yang sering diabaikan terhadap akibat hiperglikemia adalah faal paru. Ditunjukan melalui beberapa penelitian bahwa kontrol gula darah dengan pemberian insulin menyebabkan penurunan marker subklinikal inflamasi ${ }^{6}$ dan peningkatan faal paru seperti perbaikan organ-organ target yang lainnya. ${ }^{3}$ Uji faal paru yang tidak invasif dan sering digunakan adalah uji spirometri. $^{10}$

Komplikasi DM pada paru-paru karakteristiknya belum terlalu jelas. ${ }^{6,7}$ Pembuluh darah di alveolus bisa saja terkena pada komplikasi DM mikroangiopati. Namun karena terdapat cadangan yang besar, kehilangan dari mikrovaskular bisa ditoleransi tanpa perkembangan dispneu. Akibatnya mikroangiopati diabetes pada paru secara klinis belum dikenal (under-recognized). ${ }^{7}$

Penelitian yang dilakukan oleh David et al menyatakan bahwa rata-rata angka dari penurunan fungsi paru sebagaimana yang diukur dari FEV pada pasien DM tipe 2 yang tidak memiliki sejarah penyakit paru lebih besar (71 $\mathrm{ml} /$ tahun) dibandingkan penurunan fungsi paru pada kelompok tidak merokok yang sehat (25-30 $\mathrm{ml} / \mathrm{tahun}$ ). Saat diperiksa fungsi penurunan tersebut, satu-satunya prediktor dari penurunan fungsi paru adalah pada level kontrol glikemik. Peningkatan 1\% pada rata-rata Hba1c dihubungkan dengan penurunan $4 \%$ pada $\mathrm{FVC}^{6}{ }^{6}$

Komplikasi yang dapat timbul pada paru pasien DM seperti : kerusakan faal paru, penurunan kapasitas vital dan kapasitas paru total, penurunan kapasitas difusi $\mathrm{CO}_{2}$, penurunan faktor transfer $\mathrm{CO}_{2}$, penurunan ambilan $\mathrm{O}_{2}$ maskimal, penurunan otot respirasi, kelainan faal ventrikel kiri, efusi pleura, obstructive sleep apnea, infeksi, prognosis buruk pada community-acquired pnemonia, peningkatan resiko pnemonia aspirasi, infeksi mukomikosis, TB. ${ }^{3}$

\section{METODE PENELITIAN}

Penelitian ini menggunakan desain cross-sectional. Sampel pada peneltian ini berjumlah 30 orang pasien DM tipe 2 yang datang di Poli Endokrin RSUP Prof. Dr. R.D. Kandou Manado periode November sampai Desember 2014. Dilakukan informed consent serta persetujuan dari pasien. Setelah itu dilakukan anamnesis mengenai identitas, apakah pasien merokok, atau pernah menderita penyakit paru. Kemudian dilakukan pengukuran berat badan dan tinggi badan pasien. Hasil pemeriksaan lab HbA1c didapatkan melalui rekam medis atau data sekunder. Hasil lab HbA1c yang diambil adalah maksimal 2 bulan terakhir saat pasien masuk dalam penelitian. Selanjutnya pasien yang dimasukkan dalam penelitian adalah yang memenuhi kriteria inklusi (IMT $<30$, tidak merokok, tidak mempunyai riwayat 
penyakit paru). Sampel diambil sampai jumlah terpenuhi.

Pemeriksaan spirometri dilakukukan dengan menggunakan alat portable spirometer micro lab. Dilakukan oleh dokter yang sudah dilatih. Cara pengerjaan spirometri sebagai berikut :

1. Pasien dalam posisi berdiri

2. Pasien diinstruksikan memakai nose clip.

3. Mouth piece dimasukkan dalam mulut

4. Pasien menarik napas kemudian napas dihembuskan dalam mouthpiece dengan kekuatan maksimal

5. Pemeriksaan ini diulangi sampai mendapatkan 3 hasil yang terbaik

6. Hasil disimpan dalam spirometer Setelah itu hubungan kendali gula darah dengan KVP dan $\mathrm{VEP}_{1}$ diuji dengan SPSS versi 20 menggunakan uji korelasi pearson.

\section{HASIL PENELITIAN}

Dalam penelitian uji fungsi paru pada pasien DM yang dilakukan di Poli Endokrin RSUP Prof. Dr. R. D. Kandou Manado periode November 2014 sampai Desember 2014, karakteristik subjek pada penelitian ini adalah 17 orang (56,7\%) lakilaki dan 13 orang $(43,3 \%)$ perempuan, dengan rentang umur 43 sampai 65 tahun. Karakteristik kendali gula darah dalam penelitian ini, terkontrol ( HbA1c <7) adalah 7 orang $(23,3 \%)$, dan kendali gula darah tidak terkontrol (HbA1c>7) adalah 23 orang (76,7\%).

Tabel 1. Hubungan Kendali Gula Darah dengan VEP1 Pasien DM

\begin{tabular}{|c|c|c|}
\hline $\begin{array}{l}\text { Variabel } \\
\text { bebas }\end{array}$ & Statistic & VEP1 \\
\hline \multirow[t]{2}{*}{ HbA1c } & $\begin{array}{c}\text { Pearson } \\
\text { correlation }\end{array}$ & $-0,251$ \\
\hline & Sig & 0,181 \\
\hline
\end{tabular}

Dari data pada Tabel 1 dapat dilihat bahwa korelasi antara kendali gula darah dan VEP1 menggunakan Pearson
Correlation adalah $r=-0,251$. Hal ini berati bahwa kedua variabel mempunyai korelasi yang lemah karena di bawah 0,5. Tanda negatif (-) menunjukkan hal yang berlawanan. Jika kendali gula darah naik, VEP1 turun. Dan sebaliknya.

Dari nilai probabilitas antara kendali gula darah dan VEP1 didapat $\mathrm{P}=0,181$, apabila dibandingkan dengan nilai $\alpha=0,05$ (5\%) maka $\mathrm{P}>0,05(0,181>0,05)$, sehingga dapat dikatakan hubungan antara kendali gula darah dan VEP1 tidak terdapat korelasi yang signifikan.

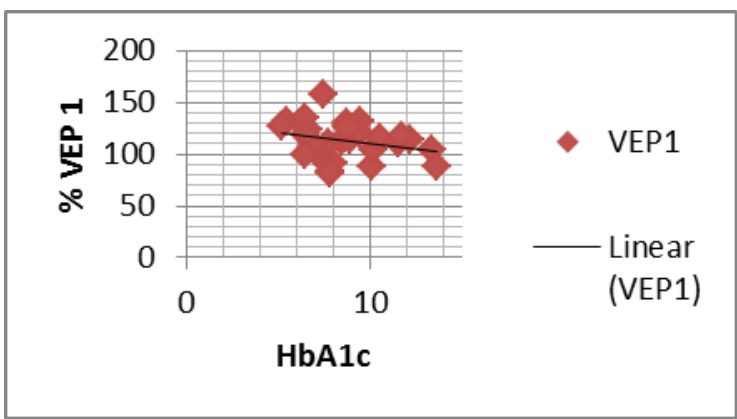

Gambar 1. Hubungan kendali gula darah dengan VEP1

Tabel 2. Hubungan Kendali Gula Darah dengan KVP Pasien DM

\begin{tabular}{ccc}
\hline $\begin{array}{c}\text { Variabel } \\
\text { Bebas }\end{array}$ & Statistic & KVP \\
\hline HbA1c & $\begin{array}{c}\text { Pearson } \\
\text { Correlation }\end{array}$ & $\begin{array}{c}- \\
0,079\end{array}$ \\
\cline { 2 - 3 } & Sig & 0,679 \\
\hline
\end{tabular}

Dari data pada Tabel 2 dapat dilihat bahwa korelasi antara kendali gula darah dan KVP menggunakan Pearson Correlation adalah $\mathrm{r}=-0,079$. Hal ini berati bahwa kedua variabel mempunyai korelasi yang lemah karena di bawah 0,5. Tanda negatif (-) menunjukkan hal yang berlawanan. Jika kendali gula darah naik, KVP turun. Dan sebaliknya.

Dari nilai probabilitas antara kendali gula darah dan KVP didapat $\mathrm{P}=0,679$, apabila dibandingkan dengan nilai $\alpha=0,05$ (5\%) maka $\mathrm{P}>0,05(0,679>0,05)$, sehingga dapat dikatakan hubungn antara kendali gula darah dan KVP tidak terdapat korelasi yang signifikan. 


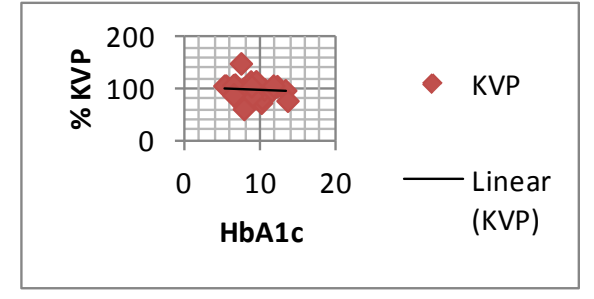

Gambar 2. Hubungan kendali gula darah dengan KVP

\section{BAHASAN}

Hubungan penurunan fungsi paru dan diabetes telah dibahas bertahun-tahun lamanya. ${ }^{6}$ Walaupun hubungan ini belum diketahui dengan pasti dan masih menjadi isu menarik untuk diteliti. ${ }^{4,6}$

Patofisiologi dari penurunan fungsi paru juga masih dalam penelitian. Mekanisme paru normal dan pertukaran gas dipengaruhi oleh integritas dari jaringan ikat paru dan mikrovaskularnya. Pengurangan dari fungsi paru sendiri dapat berhubungan dengan proses penuaan jaringan ikat, adanya glikosilasi non enzimatik, dan modifikasi dari surfaktan alveolar. ${ }^{4}$ Selain itu penurunan volume aliran darah paru dapat ditemukan. Hal ini bisa mengarah pada redistribusi sirkulasi paru, mengakibatkan ventilasi paru pada area yang masih baik dibawah perfusi. Morfologi paru pasien DM dapat mengalami perubahan yaitu terjadi penebalan membran basal alveolar yang diperkirakan terjadi pada lesi awal mikroangiopati sedangkan penebalan membran basal kapiler alveoar mendasari mikroangiopati baru pada pasien DM.,4

Subjek dengan DM bisa juga mengalami peningkatan resiko terjadinya penurunan fungsi paru sebgai hasil dari paparan yang dihirup. Sebagai contoh, pasien DM lebih rentan terhadap partikel yang ada di udara, mungkin diantaranya asap rokok. Selain itu DM juga berhubungan dengan kejadian asma pada tingkat populasi yang dipengaruhi oleh faktor imunologi dan lingkungan. ${ }^{6}$

Berdasarkan uji spirometri dengan paramater yang dinilai yaitu VEP1 dan KVP, tidak didapatkan penurunan VEP1 pada semua 30 responden, sedangkan untuk nilai KVP didapatkan penurunan nilai prediksinya $(<80 \%)$ yaitu 5 orang $(16,7 \%)$ dengan kendali gula tidak terkontrol dari 30 responden yang memperlihatkan tipe restriktif. Hasil ini sesuai dengan penelitian yang dilakukan oleh Abdul dkk dan Swati Shah dkk yang memperlihatkan penurunan kapasitas vital atau tipe restriktif pada DM tipe 2.3,4 Dari ke lima orang yang mengalami penurunan kapasitas vital (restriktif) 1 diantaranya adalah perempuan berumur 59 tahun, dan 4 orang laki-laki diantaranya berumur 56 tahun (1 orang), 59 tahun (2 orang), dan 44 tahun (1 orang). Berdasarkan data tersebut terdapat 4 orang berumur 50 -an yang mengalami penurunan kapasitas vital. Hal ini sesuai dengan teori yang mengatakan bahwa fungsi paru dipengaruhi oleh umur. ${ }^{9}$ Namun terdapat 1 orang berumur 44 tahun yang juga mengalami penurunan kapasitas vital. Hal ini mungkin dikarenakan responden memiliki riwayat selain penyakit paru yaitu stroke dan hipertensi. Sedangkan studi yang dilakukan oleh Dennis dkk menunjukkan tidak terdapat hubungan yang signifikan antara IMT, merokok, dan kontrol gula darah dengan fungsi paru. Satu-satunya variabel yang mempengaruhi penurunan fungsi paru adalah marker inflamasi yaitu C-RP. ${ }^{11}$

Dalam menghubungkan nilai VEP1 dan KVP dengan kendali gula darah (kadar HbA1c), ditemukan bahwa tidak ada hubungan yang signifikan (Tabel 1 dan 2) walaupun secara klinis terdapat penuruan KVP pada 5 orang responden dengan kendali gula darah yang tidak terkontrol (HbA1c >7\%). Beberapa studi memperlihatkan tidak terdapat korelasi antara HbA1c dengan uji fungsi paru. ${ }^{4}$

Penelitian ini memperlihatkan bahwa terdapat korelasi yang lemah dan negatif (tabel 1 dan 2) antara hasil uji fungsi paru dan kendali gula darah. Sementara beberapa studi lain menunjukkan bahwa penurunan fungsi paru berkolerasi negatif dengan Hba1c. ${ }^{4}$

Terdapat studi yang menyebutkan tidak terdapat hubungan yang signifikan 
pada pasien DM tipe 2 dengan fungsi paru. Hal ini mungkin dikarenakan sampel yang sedikit. ${ }^{4}$ Demikian pula dengan penelitian ini yang jumlah responden hanya 30 orang sehingga memberi hasil yang tidak signifikan. Selain itu kelemahan dari penelitian ini dalam menyingkirkan riwayat menderita penyakit paru pasien, tidak dilakukan foto toraks yang berfungsi mengetahui ada tidaknya gangguan pada paru walaupun belum menimbulkan gejala.

\section{SIMPULAN}

1. Terdapat penurunan nilai KVP pada beberapa subjek DM tidak terkontrol di poli endokrin RSUP Prof. Dr. R. D. Kandou Manado.

2. Tidak terdapat hubungan yang signifikan antara penurunan nilai KVP dan meningkatnya kadar HbA1c pada pasien DM di poli endokrin RSUP Prof. Dr. R.D. Kandou Manado.

3. Tidak terdapat hubungan yang signifikan antara penurunan nilai VEP1 dan meningkatnya kadar HbA1c pada pasien DM di poli endokrin RSUP Prof. Dr. R.D. Kandou Manado.

\section{SARAN}

1. Diperlukan penelitian lebih lanjut dengan jumlah sampel yang lebih besar dan variabel yang berbeda seperti mediator inflamasi.

2. DM menjadi penyakit sistemik yang perlu untuk ditatalaksana dengan baik, karena menyebabkan tipe restriktif dari perubahan mekanisme ventilasi. DM tidak terkontrol (HbA1c>7) bisa menjadi penyebab patologi pada paru.

\section{DAFTAR PUSTAKA}

1. PERKENI. Konsensus Pengelolaan dan Pencegahan Diabetes Melitus Tipe 2 di Indonesia. 2011

2. RISKESDAS. Laporan Nasional 2013
3. Malik A, Yunus F, Harahap F, Rochismandoko. Comparison of Lung Function Values in Controlled and Uncontrolled Diabetes Melitus patient in Persahabatan Hospital Jakarta. J Respir Indo. 2010;30:159-164

4. Shah S, Sanawe P, Naher P, Vaidya S, Salvi S. Pulmonary Function Test in Type 2 Diabetes Melitus and Their Association with Glicemic Control and Duration of the Disease. Lung India. April-Jun 2013;108-12

5. Wulandari D, Sugri Y. DM dan Permasalahannya pada Infeksi Tuberkulosis. J Respi Indo.2013;33:126-132

6. American Diabetes Association. Spirometry and Diabetes. diabetes Care. 2004;27:837-38

7. Muhammad I, Jabar A, Haque A, Awan S, Husain S. Pulmonary Function in Patients with Diabetes Melitus. Lung India. 2010;28:89-92

8. WHO. Definition and Diagnosis of Diabetes Melitus and Intermediatte Hyperglicaemia. 2006. Diakses tanggal 20 September 2014. Tersedia di : www.who.int/diabetes/publication/defi nition\%20and\%20diagnosis\%20of\%20 diabetes_newpdf

9. Djojoddiboto D. Respirologi. Jakarta : EGC; 2009. p. 219-21

10.American Thoracic Society. Patient Information series, Pulomonary Function Test. AM J Respir Crit Care Med. Vol 176;2007. p. 1

11.Rudolfo D, Dario M, Maria R, Pablo A, Martin R, Laura C, et al. Inadequate glucose control in type 2 diabetes is associated with imaired lung function and systemic inflammation. BMC Pulmonary Medicine. 2010:10:38:1-7

12.American Diabetes Association. Tight Diabetes Control. 2013. Tersedia di http://www.diabetes.org/living-withdiabetes/treatment-and-care/bloodglucose-control/tight-diabetescontrol.html 